\title{
Análise da fragilidade potencial e emergente do município de Canaã dos Carajás, sudeste do Estado do Pará
}

\author{
Analysis of the potential and emerging fragility of the municipality Canaã \\ dos Carajás, southeast of the state of Pará
}

\author{
Katharine Vinholte de Araújo'; André Medeiros de Andrade" \\ Leonardo Barros Dobbss"II
}

\section{RESUMO}

O município de Canaã dos Carajás se insere no universo de conflitos gerados pela disputa de território, principalmente, pela grande atividade exploratório de recursos minerais e ao avanço da agropecuária. O presente trabalho teve como objetivo analisar a Fragilidade Potencial e Emergente do município de Canaã dos Carajás, com uso de técnicas de geoprocessamento visando dar subsídios para elaboração de uma proposta de Planejamento Territorial Ambiental do município. Para os procedimentos específicos da análise da Fragilidade Potencial e Emergente, foram selecionados os atributos ambientais: declividade, tipos de solo, geologia e o uso e cobertura do solo, baseados no estudo da Análise Empírica da Fragilidade dos Ambientes Naturais e Antropizados proposta por Ross em 1994, aplicando a técnica de análise espacial de álgebra de mapa, pelo procedimento de sobreposição ponderada "Weighted Overlay". O município de Canaã dos Carajás apresenta baixa susceptibilidade natural aos processos erosivos, porém, percebe-se que as intervenções antrópicas relacionadas principalmente atividade da pecuária influenciam na sua instabilidade, potencializando a perda da qualidade ambiental no município.

Palavras-chave: fragilidade ambiental; geoprocessamento; planejamento ambiental.

\section{ABSTRACT}

The municipality of Canaã dos Carajás has conflicts caused by the dispute over territory, mainly for having many activities of exploration of mineral resources and for the advance of agriculture. This work aimed to analyze the Potential and Emerging Fragility of the municipality of Canaã dos Carajás, using geoprocessing techniques to provide subsidies for the preparation of a proposal for Environmental Territorial Planning in the municipality. To analyze the Potential and Emerging Fragility the environmental attributes were selected: slope, soil types, geology and land use and cover, based on the study of the Empirical Analysis of the Fragility of Natural and Anthropized Environments proposed by Ross in 1994. The spatial analysis technique was applied through map algebra using the weighted overlay procedure "Weighted Overlay". The municipality of Canaã dos Carajás has low natural susceptibility to erosive processes, however, it was found that anthropic interventions related mainly to livestock activity influence its instability, enhancing the loss of environmental quality in the municipality.

Keywords: environmental fragility; geoprocessing; environmental planning. 


\section{INTRODUÇÃO}

As mudanças na cobertura e uso da terra na Amazônia brasileira têm sido historicamente mais ativas, onde a expansão de pastagens e a exploração de recursos naturais são os principais fatores relacionados à redução da floresta (BÖRNER e WUNDER, 2012). Atualmente, a região amazônica é responsável por um terço da produção mineral brasileira, entretanto, a vulnerabilidade ambiental da região a colocam sujeita a muitos potenciais impactos na remoção desses recursos (CORDANI e JULIANI, 2019).

As alterações pela intervenção humana nos componentes da paisagem, como relevo, solo, recursos hídricos e cobertura vegetal, ocasionam desequilíbrios nos sistemas ambientais, que saem do seu equilíbrio natural para dinâmico, e promove a perda dos recursos naturais, em especial o solo (COUTINHO et al., 2013). E dependendo do tipo de intervenção, o grau de um impacto sobre o equilíbrio do ambiente, pode ser maior ou menor em função das características intrínsecas do ambiente, ou seja, de sua fragilidade ambiental (FRANCO et al., 2013).

Dessa maneira, Crepani et al. (2001) ressalta a grande relevância do conhecimento das formas de uso da terra, o monitoramento e o registro das informações que possibilitem a avaliação das potencialidades futuras e dos impactos produzidos pela exploração dos recursos naturais.

Nesse contexto, as aplicações de técnicas informatizadas de análises espaciais tornaram-se uma ferramenta de grande importância para se compreender o dinamismo do uso e da ocupação do solo (SCHNEIDER e TARTARUGA, 2004). Assim, a relação de aspectos físico-ambientais que integram vários elementos ambientais, proporcionam através do mapeamento e a interpretação, a compreensão da funcionalidade natural dos ambientes (PAUNGARTTEN e SANTOS, 2019). Segundo Peixoto et al. (2018); Alves et al. (2018); Furtado e Pontes (2013); Crepani et al. (2001) o estudo da fragilidade ambiental apresenta-se como importante instrumento na identificação de impactos sobre o ambiente, que permite compreender como a 
desestabilização de um sistema pode ocorrer em diferentes níveis de susceptibilidade a degradação, provocados por processos naturais ou ações antrópicas.

O princípio da funcionalidade dessa ferramenta para o planejamento territorial ambiental baseia-se na concepção das Unidades Ecodinâmicas preconizadas por Tricart (1977), onde o ambiente é analisado sob o prisma da Teoria de Sistemas, que parte do pressuposto que na natureza as trocas de energia e matéria se processam através de relações em equilíbrio dinâmico entre os componentes da paisagem. Esse equilíbrio, entretanto, pode ser alterado pelas intervenções humanas nos diversos sistemas da natureza, que podem gerar desequilíbrios temporários ou permanentes. Então Tricart (1977) definiu que os ambientes, quando estão em equilíbrio dinâmico são estáveis, quando em desiquilíbrio são instáveis.

Desse modo, como procedimento Ross (1994) propôs o modelo de fragilidade ambiental baseada na ampliação dos conceitos de Unidades Ecodinâmicas definidas anteriormente por Tricart (1977). Esse método de planejamento territorial sintetiza diferentes padrões de fragilidade em Unidades Ecodinâmicas Estáveis (Instabilidade Potencial) e Unidades Ecodinâmicas Instáveis (Instabilidade Emergente), no qual o mapa de Fragilidade Potencial representa fatores intrínsecos á suas características naturais, onde prevalece a pedogênese (PIRES et al., 2015), e o mapa de Fragilidade Emergente considera além dos fatores naturais, também as intervenções antrópicas, que refletem diretamente na forma como o homem se apropria do ambiente ao longo do tempo (PERIÇATO e SOUZA, 2019).

O mapeamento da fragilidade ambiental identifica e analisa as áreas em função de seus diferentes níveis hierárquicos, tornando-se possível a determinação do grau de fragilidade para cada região dentro de uma área de estudo, colaborando para ações tecnicamente mais adequada aos possíveis problemas ambientais (SPÖRL et al., 2004).

Dessa maneira, destaca-se que a região sudeste do Estado do Pará exibe o maior número de conflitos de impactos socioeconômicos e de reordenamento do território devido a exploração de recursos naturais (LIMA e SILVA, 2016). Logo, o município de Canaã dos Carajás se insere nesse universo de conflitos gerados pela disputa de 
território, principalmente, pela grande atividade exploratório de recursos minerais e ao avanço da agropecuária (LOPES et al., 2018). Torna-se, então, de fundamental importância as informações das formas atuais de uso do solo ocorrentes no município, pois a identificação das suas fragilidades (potencial e emergente) indicam quais áreas requerem maior atenção para conservação do equilíbrio ambiental, e permitem melhor definição de diretrizes e ações a serem implementadas no espaço físico-territorial (VALLE et al., 2016).

Dado o exposto, o presente trabalho teve como objetivo analisar a Fragilidade Potencial e Emergente do município de Canaã dos Carajás (PA), com uso de técnicas de geoprocessamento visando dar subsídios para elaboração de uma proposta de Planejamento Territorial Ambiental do município.

\section{MATERIAL E MÉTODOS}

\subsection{Localização e caracterização da área de estudo}

Canaã dos Carajás é um município do Estado do Pará com aproximadamente 37.085 habitantes (IBGE, 2019). Sua área territorial é de 3144,98 km² e encontra-se na latitude de 6²9'51"S, longitude 4952'42"O, localizada na Mesorregião Sudeste Paraense, Microrregião Parauapebas (figura 1).

Apresenta clima tropical com estação seca, classificação com Aw (clima tropical de savana) de acordo com Köppen e Geiger (1928) e temperatura média anual de 25,4 ${ }^{\circ} \mathrm{C}$. A pluviosidade média anual de é de $1.766 \mathrm{~mm}$, onde o mês mais seco é julho, com média de $18 \mathrm{~mm}$ de chuva e o mês com maior precipitação é março, com média de $290 \mathrm{~mm}$ (CLIMATE-DATA, 2019).

Os solos ocorrentes na área de estudo são predominantemente classificados em Argissolos vermelho-amarelos distróficos, e ocorrem ainda na região outras duas classes de solo de forma mais abrangente como Latossolos vermelho-amarelos distróficos e Neossolos Litólicos distróficos (ICMBio, 2016). Exibe uma estrutura 
geológica complexa, definida por uma variação acentuada de rochas de idade précambriana, inseridas dentro do Complexo Xingu (FEIO e DALL'AGNOL, 2012).

As tipologias vegetação de maior representatividade são a Floresta Ombrófila Aberta, Floresta Ombrófila Densa e Campo Rupestre Ferruginoso, onde cerca de 10\% de sua área de floresta está localizada na região da Floresta Nacional de Carajás (ICMBio, 2017).

Figura 1- Localização do município de Canaã dos Carajás, estado do Pará

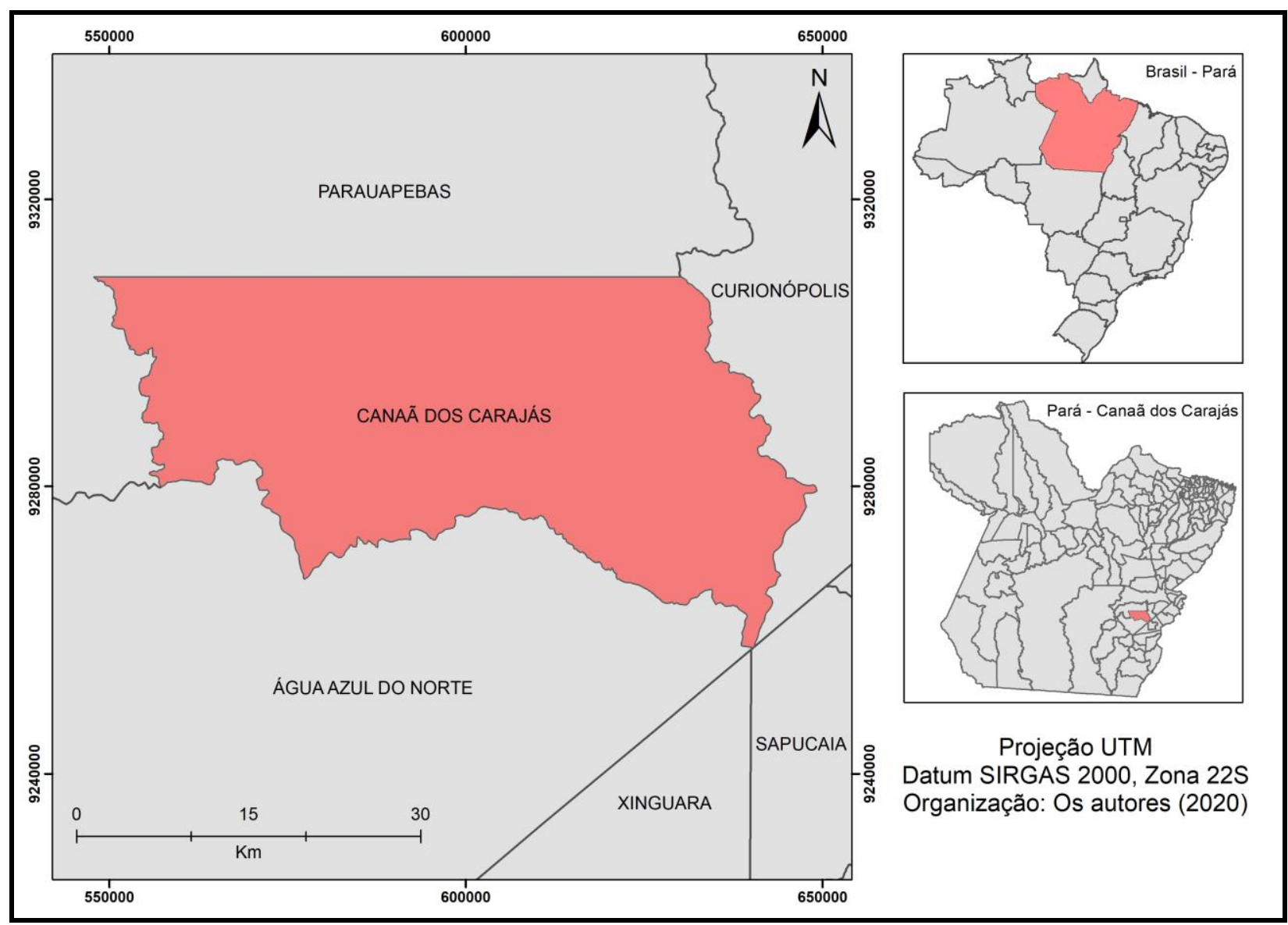

Fonte: Elaborado pelos autores

A economia do município é estruturada principalmente por atividades de exploração mineral (ferro, cobre e níquel), tendo a mineradora Vale, através da Mineração da Serra do Sossego como principal promotora do desenvolvimento econômico municipal, e em atividades da pecuária, além de setor imobiliária, agricultura urbana, apicultura, artesanato e serviços informais (CARDOSO et al., 2018). 
Além disso, o município está situado em uma área geográfica que se interliga com as várias cidades importantes, as quais integram o conjunto de municípios com grande dinâmica econômica, por conta da indústria extrativa mineral ou pela agropecuária como os municípios de Marabá, Parauapebas, Curionópolis, Ourilândia do Norte, Tucumã, São Félix do Xingu, Santana do Araguaia, Altamira e outros tantos municípios no estado de Mato Grosso e Tocantins (SEMDEC, 2016).

\subsection{Aquisição de informações do terreno}

Para os procedimentos específicos para a análise da Fragilidade Potencial e Fragilidade Emergente do município de Canaã dos Carajás, foram selecionados e realizado o levantamento cartográfico dos seguintes atributos ambientais: declividade do terreno, tipos de solo, geologia e o uso e cobertura do solo, baseados no estudo da Análise Empírica da Fragilidade dos Ambientes Naturais e Antropizados proposta por Ross em 1994.

Destaca-se que a seleção dos atributos ambientais neste trabalho, tomou-se como base a suscetibilidade à erosão das superfícies principalmente em decorrência das suas variações morfológicas.

A base cartográfica para elaboração do mapa das classes de declividade do município de Canaã dos Carajás foi obtida a partir de dados de imagem SRTM (Suttle Radar Topografic Mission) com uma resolução original de 90 metros da Empresa Brasileira de Pesquisa Agropecuária (EMBRAPA) com escala 1:50.000, utilizando-se os limites de declividade considerados críticos para geotecnia preconizados por Ross (1994) de 0 a 6\%, 6 a 12\%, 12 a 20\%, 20 a 30\%, e maior que 30\%.

Em relação as informações sobre o levantamento para elaboração do mapa das classes de solos foram obtidas através dos dados disponibilizados em formato digital do tipo shapefile da Pedologia da Amazônia Legal, escala 1:250.000 fornecidos pelo sitio eletrônico do Instituto Nacional de Dados Espaciais (INDE), que foram organizados seus vetores e posteriormente atribuídas as cores e a nomenclatura de cada classe de solos de acordo com a manual técnico de pedologia do IBGE (2007). 
Quanto a base cartográfica para a obtenção das classes das unidades geológicas do município, procederam dos dados geológicos do tipo shapefile do estado do Pará, escala 1:1.000.000 disponíveis sitio de dados espaciais do Serviço Geológico do Brasil, organizados pela Companhia de Pesquisa de Recursos Minerais (CPRM).

As informações do uso e cobertura do solo foram obtidas através de dados digitais resultantes do mapeamento da Terra da Amazônia Legal (Projeto TerraClass/INPE/CRA) que são disponibilizados pelo Instituto Nacional de Pesquisas Espaciais (INPE) representada com base na imagem de satélite Landsat 8 (sensor OLI) com 30m de resolução espacial. Foram atribuídas as cores de cada classe de mapeamento da cobertura e uso do solo de acordo com a manual técnico de uso do solo do IBGE (2013).

O tratamento dos arquivos matriciais e vetoriais e a elaboração dos mapas dos atributos avaliados do município foram realizados via ferramentas do Sistema de Informação Geográfica (SIG) QGIS®, versão 3.12.1.

\subsection{Definição das classes de fragilidade dos atributos do terreno}

Os critérios de classificação das classes de fragilidade foram definidos em função de sua maior ou menor fragilidade frente aos processos erosivos e instabilização das vertentes, de modo que receberam uma classificação não-paramétrica e qualitativa, que variam de 1 a 5 conforme a sua contribuição para a fragilidade do ambiente de acordo com Ross (1994) e Crepani et al. (2001). Sendo que os pesos estão relacionados respectivamente às seguintes classes: Muito fraca (1), Fraca (2), Média (3), Forte (4), e Muito forte (5).

Dessa forma, na tabela 1 encontra-se as classes de fragilidade da declividade definida a partir da hierarquização da vulnerabilidade do terreno já consagrados nos estudos de aptidão agrícola associados aos limites considerados críticos para geotecnia de Ross (1994), que são indicativos do vigor dos processos erosivos, dos riscos de escoamento/deslizamento e inundações frequentes. 
Tabela 1 - Fragilidade das classes de declividade do município de Canaã dos Carajás (PA)

\begin{tabular}{lll}
\hline Classes de Declividade & Classes de Fragilidade & Peso \\
\hline Até $06 \%$ & Muito baixa & 1 \\
\hline De 6 a $12 \%$ & Baixa & 2 \\
\hline De 12 a 20\% & Média & 3 \\
\hline De 20 a 30\% & Alta & 4 \\
\hline Maior que 30\% & Muito alta & 5 \\
\hline Fonte: Ross (1994) & &
\end{tabular}

Os critérios para a determinação dos pesos para os tipos de solo foram conforme o proposto por Ross (1994), além das características referentes a susceptibilidade a erosão segundo a EMBRAPA (2006), onde a vulnerabilidade quanto a textura corresponde de muito argilosa/argilosa cascalhenta (pouco susceptíveis) média/argilosa cascalhenta (susceptíveis) - média/cascalhenta (muito susceptíveis), respectivamente para os solos relacionados na tabela 2.

Tabela 2 - Fragilidade das classes pedológicas município de Canaã dos Carajás (PA)

\begin{tabular}{lll}
\hline Classes Pedológicas & Classes de Fragilidade & Peso \\
\hline Latossolo Vermelho Distrófico & Muito baixa & 1 \\
\hline Argissolo Vermelho-Amarelo Distrófico & Média & 3 \\
\hline Neossolo Litólico Distrófico & Muito alta & 5 \\
\hline Fonte: Ross (1994). & &
\end{tabular}

As classes geológicas, por sua vez, foram classificadas conforme Crepani et al. (2001), que atribuíram posições relativas e empíricas para as rochas mais comumente encontradas, dentro de uma escala de vulnerabilidade à denudação (intemperismo + erosão), conforme descritas no Quadro 1.

Dessa maneira, para este trabalho a escala utilizada foi adaptada, levando em consideração os graus de fragilidade de Muito baixa a Muito Forte (1 a 5), contudo sendo proporcional os valores estabelecidos por Crepani et al. (2001), onde os valores mais próximos à estabilidade foram atribuídos peso mais próximos a 1, ou seja, que apresentem a menor intensidade de dissecação. E da mesma forma as unidades de paisagem natural que apresentem as maiores intensidades de dissecação, recebem 
valores da escala de vulnerabilidade mais próximos de 5, ou seja, próximos da vulnerabilidade (tabela 3).

Quadro 1 - Escala de vulnerabilidade à denudação das rochas mais comuns

\begin{tabular}{|c|c|c|c|c|c|}
\hline \multicolumn{6}{|c|}{ Escala de vulnerabilidade à denudação das rochas mais comuns } \\
\hline $\begin{array}{l}\text { Quartzitos ou } \\
\text { Metaquartzitos }\end{array}$ & 1,0 & $\begin{array}{c}\text { Milonitos, Quartzo, } \\
\text { Muscovita, Biotita, Clorita } \\
\text { xisto }\end{array}$ & 1,7 & $\begin{array}{c}\text { Arenitos quartzosos ou } \\
\text { ortoquartzitos }\end{array}$ & 2,4 \\
\hline Riólito, Granito, Dacito & 1,1 & Piroxenito, Anfibolito,Dunito & 1,8 & $\begin{array}{l}\text { Conglomerados, } \\
\text { Subgrauvacas }\end{array}$ & 2,5 \\
\hline $\begin{array}{l}\text { Granodiorito, Quartzo } \\
\text { Diorito, Granulitos }\end{array}$ & 1,2 & $\begin{array}{l}\text { Hornblenda, Tremolita, } \\
\text { Actinolita xisto }\end{array}$ & 1,9 & Grauvacas, Arcózios & 2,6 \\
\hline Migmatitos, Gnaisses & 1,3 & $\begin{array}{c}\text { Estaurolita xisto, Xistos } \\
\text { granatíferos }\end{array}$ & 2,0 & Siltitos, Argilitos & 2,7 \\
\hline $\begin{array}{l}\text { Fonólito, Nefelina, } \\
\text { Sienito, Traquito, Sienito }\end{array}$ & 1,4 & Filito, Metassiltito & 2,1 & Folhelhos & 2,8 \\
\hline Andesito, Diorito, Basalto & 1,5 & Ardósia, Metargilito & 2,2 & $\begin{array}{c}\text { Calcários, Dolomitos, } \\
\text { Margas, Evaporitos }\end{array}$ & 2,9 \\
\hline $\begin{array}{l}\text { Anortosito, Gabro, } \\
\text { Peridotito }\end{array}$ & 1,6 & Mármores & 2,3 & $\begin{array}{c}\text { Sedimentos } \\
\text { Inconsolidados: Aluviões, } \\
\text { Colúvios etc. }\end{array}$ & 3,0 \\
\hline
\end{tabular}

Fonte: Crepani et al. (2001)

Tabela 3 - Fragilidade das classes geológicas município de Canaã dos Carajás (PA)

\begin{tabular}{|c|c|c|}
\hline Classes Geológicas (categoria das rochas) & Classes de Fragilidade & Peso \\
\hline $\begin{array}{l}\text { Granito Planalto (Granito); Granito Plaquê } \\
\text { (Granodiorito); Formação Parauapebas } \\
\text { (Basalto); }\end{array}$ & Muito Baixa & 1 \\
\hline $\begin{array}{l}\text { Diorito Cristalino (Clorita xisto); Granito Rio } \\
\text { Branco (Diorito); Grupo Sapucaia (Clorita } \\
\text { xisto); Ultramáficas Vermelho (Gabro e } \\
\text { Peridolito); Complexo Xingu (Diorito) }\end{array}$ & Baixa & 2 \\
\hline $\begin{array}{l}\text { Formação Carajás (Jaspilito); Granito Serra } \\
\text { dos Carajás (Quartzo Estaurolita xisto) }\end{array}$ & Média & 3 \\
\hline Formação Águas Claras (Siltito) & Muito alta & 5 \\
\hline
\end{tabular}

Com relação às classes de uso e cobertura do solo exposta na tabela 4, a classificação foi realizada de acordo com os critérios propostos por Ross (1994), que determina uma hierarquização a partir dos seus graus de proteção ao solo, obedecendo a uma ordem decrescente dessa capacidade de proteção. Portanto, uma área de floresta natural ou plantada desempenha uma maior proteção ao solo, que 
também variam da mais protetora a menos protetora. Da mesma forma, que uma área de pastagem ou agricultura, que por sua vez, manifestam-se mais favoráveis a menor capacidade de proteção do solo.

Tabela 4 - Graus de proteção do solo das classes de uso e cobertura do solo do município de Canaã dos Carajás (PA)

\begin{tabular}{lcc}
\hline Usos e cobertura do solo & Graus de Proteção & Peso \\
\hline $\begin{array}{l}\text { Floresta; Vegetação secundária; Área não } \\
\text { observada }\end{array}$ & Muito alta & 1 \\
\hline $\begin{array}{l}\text { Reflorestamento; Regeneração com } \\
\text { pastagem }\end{array}$ & Alta & 2 \\
\hline $\begin{array}{l}\text { Pastos sujo; Pasto limpo } \\
\text { Pasto com solo exposto; Não florestada; }\end{array}$ & Média \\
$\begin{array}{l}\text { Mineração; Desflorestamento; Área } \\
\text { Urbana; Mosaico de ocupações; Corpos } \\
\text { d'água }\end{array}$ & Muito baixa ou nula \\
Fonte: Ross (1994)
\end{tabular}

\subsection{Mapeamento da fragilidade potencial e emergente}

Os procedimentos para a análise da Fragilidade Potencial e Fragilidade Emergente constituíram na aplicação da técnica de análise espacial de álgebra de mapa, pelo procedimento de sobreposição ponderada "Weighted Overlay", que é aplicada sobre planos de informação reclassificados com seus respectivos pesos, atribuindo-Ihes os códigos de fragilidade e os valores em porcentagem da influência que exercem sobre os processos ambientais em análise, onde o somatório dos valores em porcentagem da influência para cada uma das informações deve totalizar 100\%. Dessa forma, foram atribuídos e realizado a aplicação da técnica como representado no Quadro 2.

Nota-se que, para a elaboração do mapa de Fragilidade Potencial considerou-se o cruzamento dos aspectos físicos naturais do ambiente (declividade, solos e geologia), o que indica fragilidade natural do município a erosão. De acordo com Martins e Rodrigues (2012) a espacialização dos processos erosivos relacionados a 
geomorfologia são a base para o entendimento da morfodinâmica. Sendo assim, a declividade do terreno apresentou destaque junto à ponderação dos atributos.

Quadro 2 - Valores ponderados para os atributos ambientais do munícipio município de Canaã dos Carajás (PA)

\begin{tabular}{|c|c|c|c|}
\hline \multicolumn{2}{|c|}{ Fragilidade Potencial } & \multicolumn{2}{|l|}{ Fragilidade Emergente } \\
\hline Atributos & $\begin{array}{l}\text { Ponderação } \\
\text { (\%) }\end{array}$ & Variáveis & $\begin{array}{l}\text { Ponderação } \\
\text { (\%) }\end{array}$ \\
\hline Declividade & 45 & $\begin{array}{l}\text { Mapa de Fragilidade } \\
\text { Potencial }\end{array}$ & 50 \\
\hline Solos & 35 & $\begin{array}{l}\text { Mapa de Uso/cobertura do } \\
\text { solo }\end{array}$ & 50 \\
\hline Geologia & 20 & & \\
\hline Total & 100 & (6) & 100 \\
\hline
\end{tabular}

Fonte: Elaborado pelos autores

Os solos participam da caracterização morfodinâmica das unidades de paisagem natural, fornecendo o indicador básico da posição ocupada pela unidade dentro da escala gradativa da Ecodinâmica: a maturidade dos solos, que representam peso significativo no estudo da fragilidade do ambiente (CREPANI et al., 2001). Logo, a contribuição da geologia estende-se a história da evolução geológica do ambiente onde a unidade se encontra e as informações relativas ao grau de coesão das rochas que a compõem. Dessa forma, foi considerado influência menor perante os atributos anteriores.

Para o produto do mapeamento da Fragilidade Emergente empregou-se a sobreposição ponderada do mapa de Fragilidade Potencial com o mapa de uso e cobertura do solo, que demonstra a situação ambiental atual perante as intervenções antrópicas, bem como, os graus de suscetibilidade à erosão a qual está exposta a área de estudo. 


\section{RESULTADOS E DISCUSSÃO}

A análise da declividade do terreno é um fator topográfico muito importante, que representa o principal condicionador de atividades desenvolvidas, principalmente relacionadas a capacidade de uso ou aptidão agrícola das terras, além de indicar os riscos de processos erosivos, deslizamento e inundações (TREVISAN e MOSCHINI, 2016).

Dessa forma, a partir da análise do mapa de declividade (figura 2) verificou-se que áreas com declividade até $6 \%$ (fragilidade muito baixa) são predominantes no município de Canaã dos Carajás, que abrange uma área total de 51,43\%, consideravelmente sendo uma área de relevos planos e/ou com suaves ondulações.

Figura 2 - Declividade do município de Canaã dos Carajás (PA)

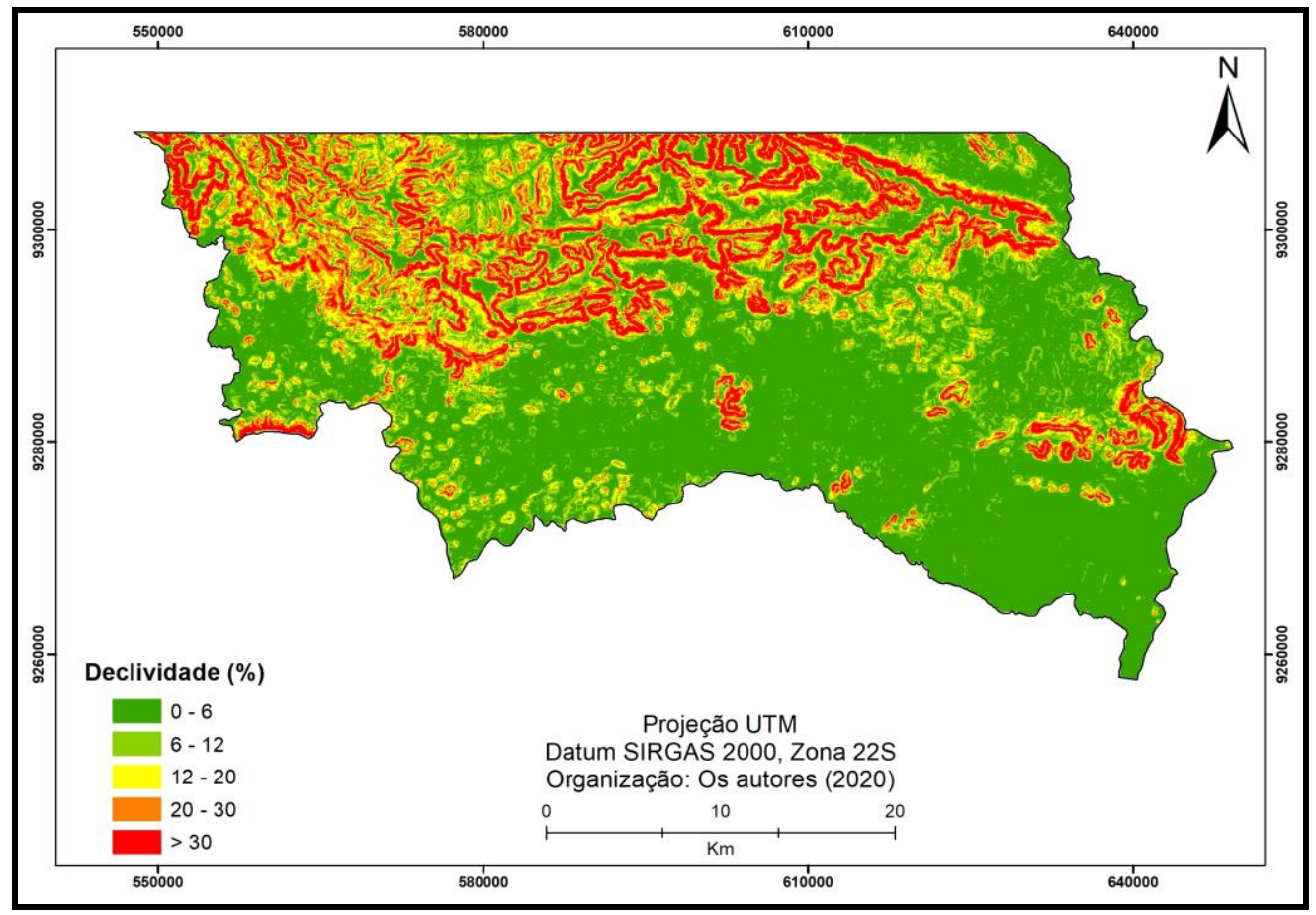

Fonte: Elaborado pelos autores

Por seguinte, áreas com declividade de 6 a 12\% (fragilidade fraca) correspondem a 16,50\% da área, como pode ser observado na tabela 5. Destaca-se uma representativa parcela de relevo acidentado (acima de 30\%), equivalente a 11,44\% da área total do terreno com inclinações muito fortes, verificou-se que o valor máximo 
de declividade foi de 98,24\%. Nesses locais, a fragilidade ambiental passa a ser considerada como muito Forte, pois relevos mais declivosos possuem fator de maior impacto na taxa de perda de solo por erosão (CAMPOS et al., 2008). Já, as áreas com menor representatividade foram são as classes de 12 a 20\% e 20 a 30\%, expondo, respectivamente, $11,43 \%$ e 9,19\% da área.

Tabela 5 - Áreas absolutas e relativas das classes de declividade do município de Canaã dos Carajás (PA)

\begin{tabular}{lcc}
\hline Declividade & Área $\left.\mathbf{( K m}^{\mathbf{2}}\right)$ & Área $\mathbf{( \% )}$ \\
\hline Até $06 \%$ & 1602,87 & 51,43 \\
\hline De 6 a 12\% & 514,26 & 16,50 \\
\hline Maior que 30\% & 356,55 & 11,44 \\
\hline De 12 a 20\% & 356,33 & 11,43 \\
\hline De 20 a 30\% & 286,52 & 9,19 \\
\hline
\end{tabular}

Fonte: Elaborado pelos autores

Apesar do município expor áreas potencialmente menos frágeis, destaca-se que se nestas áreas, o uso e o manejo do solo não considerarem a sustentabilidade ambiental do agroecossistema, podem ocorrer prejuízos ambientais e econômicos (ALVES et al., 2018). Storto e Cocato (2018) reforçam ainda que para evitar riscos de movimentação de massa, erosão e perda do solo, é necessário que seu uso e ocupação seja planejado de maneira apropriada.

Os três tipos de solo ocorrentes na área de estudo são: Argissolo VermelhoAmarelo distrófico, Neossolos Litólicos distróficos e Latossolos Vermelho-Amarelos distróficos (figura 3).

A classe de Argissolo Vermelho-Amarelo distrófico é predominante no município, incidindo principalmente nas regiões menos declivosas. Como observados na tabela 6 está presente em mais da metade do território, ocupando uma área de 1.773,28 km² (56,40\%). O Argissolo Vermelho-Amarelo distróficos possui textura média/argilosa cascalhenta, de perfil menos desenvolvido (pouco profundos) e com baixa fertilidade natural (IBGE, 2007). O grau de erodibilidade desse solo tem como fator determinante 
a presença de horizonte B textural, que influencia a erosão superficial, implicando no alto risco de erosão e a sua baixa fertilidade natural na restrição do seu uso agrícola (ALVES et al., 2018).

Figura 3 - Tipos de solo do município de Canaã dos Carajás (PA)

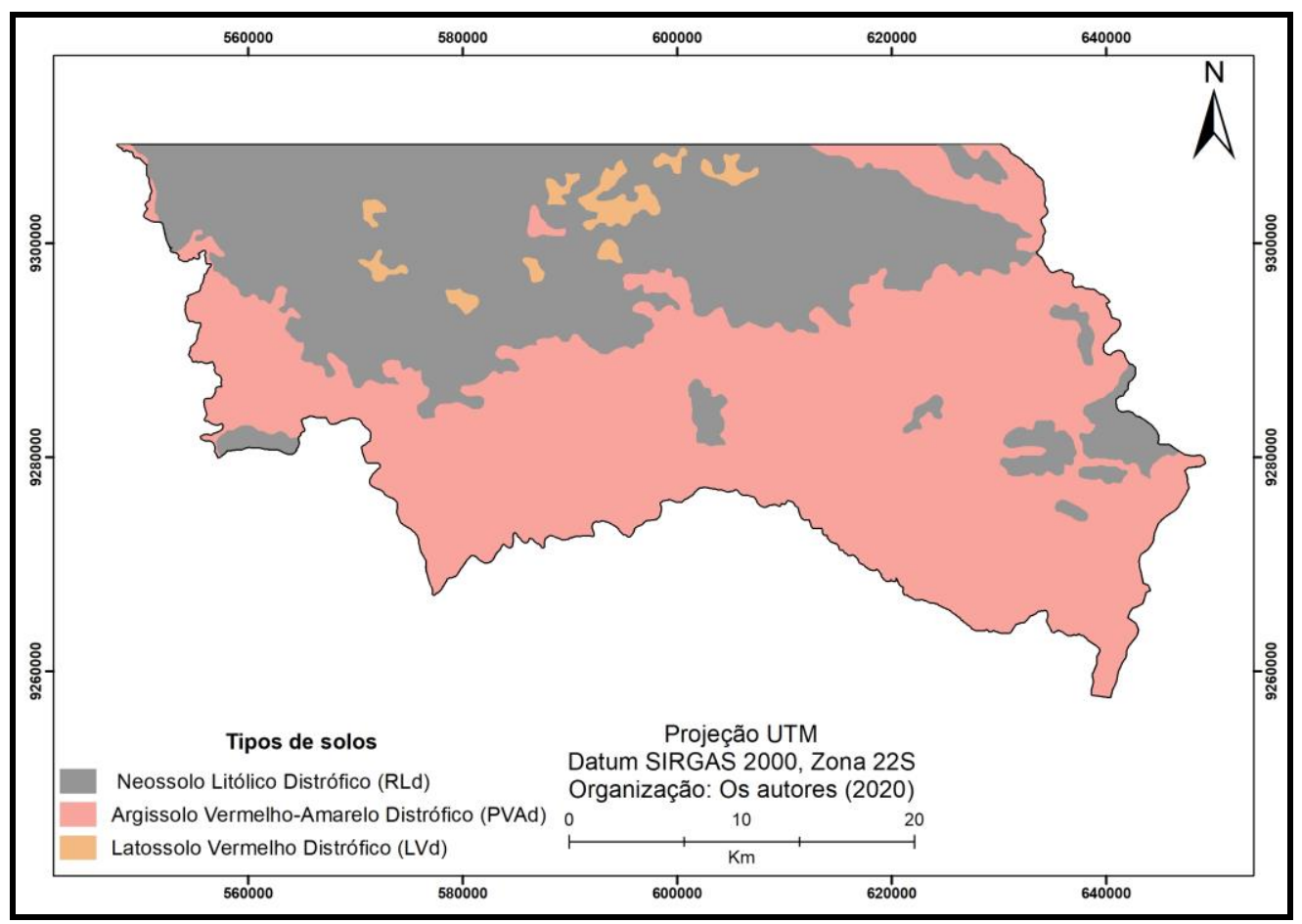

Fonte: Elaborado pelos autores

Tabela 6 - Áreas absolutas e relativas das classes dos tipos de solos do município de Canaã dos Carajás (PA).

\begin{tabular}{lcc}
\hline Tipos de Solos & Área $\left.\mathbf{( K m}^{\mathbf{2}}\right)$ & Área (\%) \\
\hline Argissolo Vermelho-Amarelo Distrófico & 1773,28 & 56,40 \\
\hline Neossolo Litólico Distrófico & 1316,15 & 41,86 \\
\hline Latossolo Vermelho Distrófico & 54,73 & 1,74 \\
\hline Fonte: Elaborado pelos autores & &
\end{tabular}

O Neossolo Litólico distrófico, por sua vez, ocupa 41,86\% do território, predominantemente nas regiões de relevos muito acidentados do município, cujo corresponde a uma fragilidade muito forte, pois são solos normalmente com pequena profundidade e pedregosidade que dificultam a penetração e a exploração 
de água e nutrientes pelas raízes das plantas e são frequentemente utilizados para pastagens (CORADO NETO et al., 2015).

Ocorre em apenas 1,74\% da área o Latossolos Vermelho-Amarelo distrófico, que são predominantemente hidromórficos, profundos ou muito profundos e bem drenados, que em condições naturais apresentam boa resistência aos processos erosivos, atribuindo-Ihe uma muito baixa vulnerabilidade a processos erosivos (ALVES et al., 2018). Em geral, possui grandes problemas fertilidade, porém pode apresentar boa produtividade agrícola e pecuária com manejo adequado (OLIVEIRA et al., 2012).

A geologia da área de estudo apresenta um diversificado conjunto de doze unidades geológicas (figura 4). Segundo Crepani et al. (2001) o grau de coesão das rochas é a informação básica da Geologia a ser integrada a partir da Ecodinâmica, uma vez que em rochas pouco coesas prevalecem os processos modificadores das formas de relevo, enquanto que nas rochas bastante coesas prevalecem os processos de formação de solos.

Figura 4 - Classes geológicas município de Canaã dos Carajás (PA)

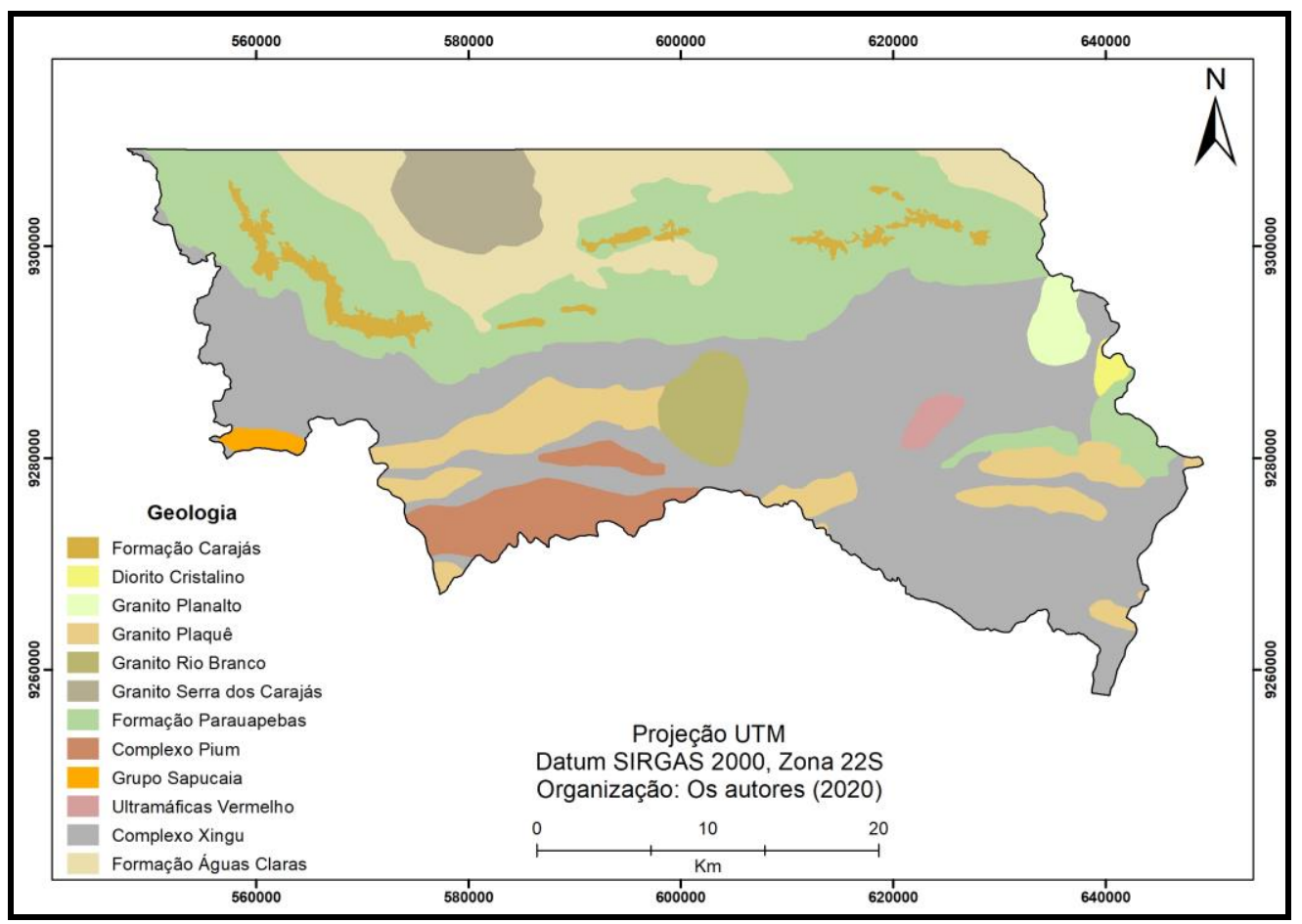

Fonte: Elaborado pelos autores 
Na tabela 7 verifica-se a predominância da unidade Complexo Xingu com área absoluta de 1.254,74 $\mathrm{km}^{2}$ (39,89\%), que apresenta um grau de fragilidade fraca, correspondente aos tipos de rochas ígneas que é composta: diorito, gnaisse, granitoide, granulito e metamáfica (OLIVEIRA et al., 2018). A composição química das rochas ígneas que apresenta essa unidade geológica exibe boa resistência ao intemperismo. No entanto, a taxa de intemperismo de um mineral depende de vários outros fatores além de sua estrutura e composição química, tais como: forma e tamanho do cristal, perfeição e pureza do cristal, porosidade da rocha para acesso da água (CREPANI et al., 2001).

Tabela 7 - Áreas absolutas e relativas das classes geológicas do município de Canaã dos Carajás (PA)

\begin{tabular}{lcc}
\hline Unidades Geológicas & Área $\mathbf{( K m}^{\mathbf{2}} \mathbf{)}$ & Área (\%) \\
\hline Complexo Xingu & 1254,74 & 39,89 \\
\hline Formação Parauapebas & 875,43 & 27,83 \\
\hline Formação Águas Claras & 326,85 & 10,39 \\
\hline Granito Plaquê & 219,74 & 6,99 \\
\hline Complexo Pium & 132,84 & 4,22 \\
\hline Granito Serra dos Carajás & 115,47 & 3,67 \\
\hline Formação Carajás & 74,18 & 2,36 \\
\hline Granito Rio Branco & 68,79 & 2,19 \\
\hline Granito Planalto & 36,17 & 1,15 \\
\hline Ultramáficas Vermelho & 17,34 & 0,55 \\
\hline Grupo Sapucaia & 14,08 & 0,45 \\
\hline Diorito Cristalino & 9,61 & 0,31
\end{tabular}

Fonte: Elaborado pelos autores

Outra unidade que se destaca é a Formação Parauapebas (basalto, metabasalto, metadacito, metarriolito) rocha ígnea compacta, de alta resistência mecânica devido à granulação fina, presente em 27,83 \% do território, cuja classificação de fragilidade é média. Seguida pela Formação Águas Claras (siltito, arenito, pelito), que ocupa 10,39\% da área. As rochas que a compõe são sedimentares. O siltito, por exemplo, é formada pela deposição e litificação de sedimentos com grãos de tamanho silte, intermediário 
entre os tamanhos areia e argila. De maneira geral, as rochas predominantes na Formação Águas Claras exibem altos índices de vulnerabilidade à denudação, considerada com fragilidade muito forte, o que requer cuidados especiais.

Na figura 5 é possível perceber como ocorre a distribuição dos diferentes tipos de uso do solo ao longo do território.

Figura 5 - Uso e cobertura do solo do município de Canaã dos Carajás (PA)

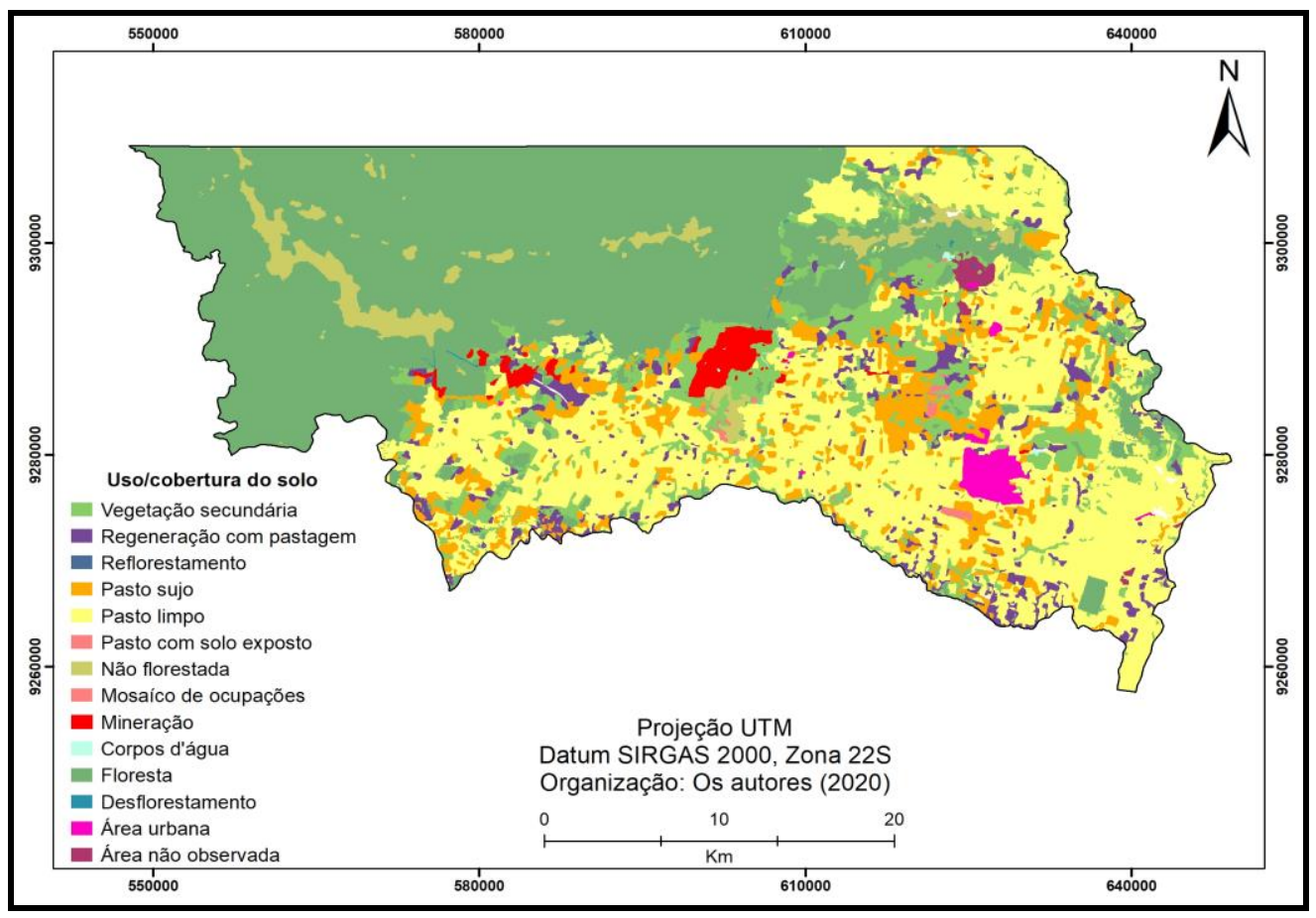

Fonte: Elaborado pelos autores

Observa-se na tabela 8 a predominância de Floresta tropical não alterada que ocupa $41,56 \%$ do território, sendo que grande parte das áreas florestadas desta região estão em áreas de proteção, que pertencem à região da Floresta Nacional de Carajás e aos limites do Parque Nacional dos Campos Ferruginosos, consideradas áreas mais estáveis, de modo que a cobertura do solo por vegetação densa representa um obstáculo mecânico ao livre escoamento superficial da água, portanto, considerado um grau de proteção maior ao solo (ALVES et al., 2018). 
Tabela 8 - Áreas absolutas e relativas das classes de uso e cobertura do solo do município de Canaã dos Carajás (PA)

\begin{tabular}{lcc}
\hline Uso e cobertura do solo & Área $\left.\mathbf{( K m}^{\mathbf{2}}\right)$ & Área $\mathbf{( \% )}$ \\
\hline Floresta & 1304,71 & 41,53 \\
\hline Pasto limpo & 973,10 & 30,97 \\
\hline Vegetação secundária & 300,42 & 9,56 \\
\hline Pasto sujo & 252,94 & 8,05 \\
\hline Regeneração com pastagem & 115,70 & 3,68 \\
\hline Não florestada & 104,27 & 3,32 \\
\hline Mineração & 38,28 & 1,22 \\
\hline Área Urbana & 28,59 & 0,91 \\
\hline Área não observada & 10,87 & 0,35 \\
\hline Mosaico de ocupações & 8,08 & 0,26 \\
\hline Corpos d'água & 2,23 & 0,07 \\
\hline Desflorestamento & 1,39 & 0,04 \\
\hline Reflorestamento & 1,24 & 0,04 \\
\hline Pasto com solo exposto & 0,08 & 0,00 \\
\hline
\end{tabular}

Fonte: Elaborado pelos autores

Sequencialmente, nota-se resultados significativos para as áreas de pastagens manejadas (pasto limpo), correspondente a $30,97 \%$ da área e pastos sujos, áreas cujo possuem a presença de plantas invasoras, ou seja, não manejadas representaram 8,05\% da área. Segundo o INPE em 2014 as áreas de pastagem corresponderam cerca de 60\% do uso das terras desflorestadas na Amazônia Legal.

Na figura 6 é possível observar o levantamento histórico de dinâmica do uso e ocupação do solo do município de Canaã dos Carajás fornecidos pelo sitio eletrônico do MapBiomas (2020) que confirma com a estatística ao longo do período de 1988 a 2018 (30 anos) houve redução de 56,80\% de áreas de floresta, contrastando com aumento significativo de 154,35\% áreas de pastagem destinadas a agropecuária.

Quanto ao grau de proteção do solo, a pastagem proporciona média fragilidade, pois apesar dos efeitos benéficos das raízes das gramíneas no aumento da agregação do solo, o manejo inadequado com número excessivo de animais por hectare e o aumento da declividade da vertente, proporcionam o aumento da resistência à penetração de raízes e a diminuição dos valores de infiltração, favorecendo também 
o escoamento superficial e a ocorrência dos processos erosivos nos horizontes superficiais (MEDEIROS et al., 2018).

Figura 6 - Áreas de floresta e pastagem do município de Canaã dos Carajás entre os anos de 1988 a 2018

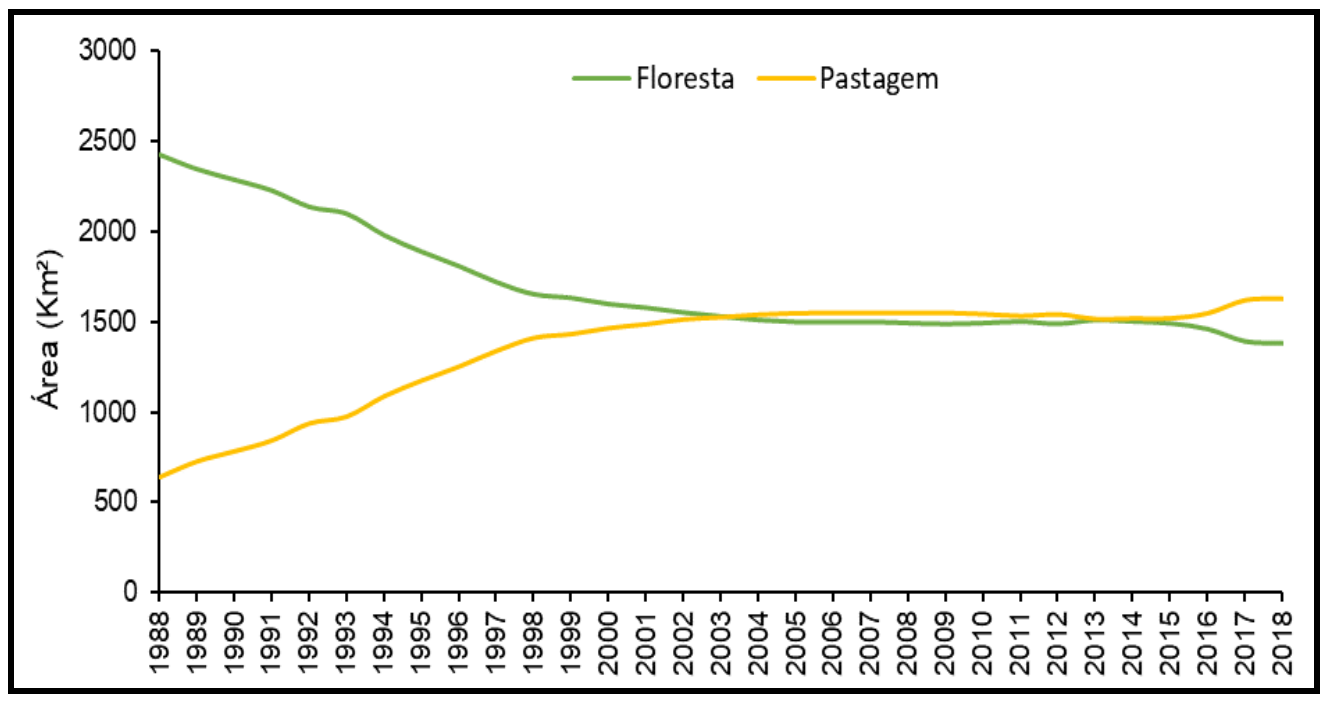

Fonte: Elaborado pelos autores

As áreas de vegetação secundária ocupam uma área de 9,56\% e 3,68\% são representadas por áreas em processo de regeneração com pastagem, que apresentam uma fragilidade baixa, pois proporcionam significativa cobertura do solo. Essas condições correspondem a áreas em processo natural de regeneração da vegetação típica, que passaram por algum tipo de intervenção, geralmente, por queimadas, corte raso, uso para agricultura ou pastagem (OLIVEIRA et al., 2016).

Destaca-se também, o uso do território do município para a mineração, desflorestamento, ocupação urbana, solo exposto e não florestada (afloramento rochoso) corresponderam as áreas mais instável, representam conjuntamente um total de 5,50\%. Estas áreas são desprovidas de vegetação ou cultura, que dificulta a infiltração da água no solo e a criação de barreiras que impeçam o aumento da energia cinética do escoamento superficial, e que, sendo assim, atinge uma grande 
capacidade de transportar sedimentos (PINESE JÚNIOR et al., 2008). Expondo assim, fragilidade muito forte, uma vez que são áreas mais suscetíveis a sofrer erosão.

O mapeamento da fragilidade potencial, com base na integração das variáveis físicas do terreno (declividade, solos e geologia) evidencia os graus de fragilidade potencial natural à erosão de Muito baixa a Muito alta como pode ser observado na figura 7.

Figura 7 - Fragilidade Potencial do município de Canaã dos Carajás (PA)

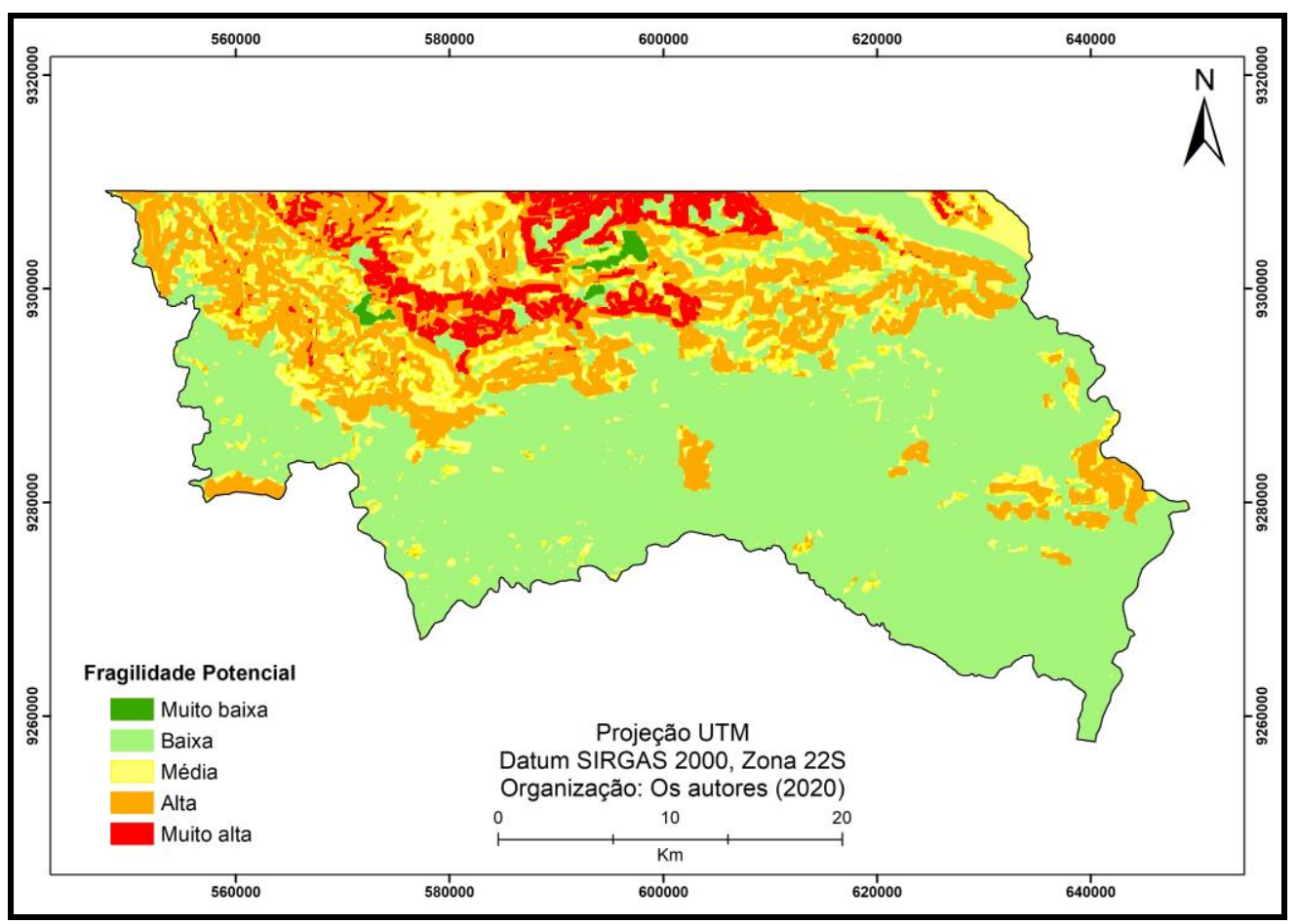

Fonte: Elaborado pelos autores

Constatou-se que a Fragilidade Potencial Baixa predomina uma área que ocupa $56,26 \%$ de extensão (tabela 9), que estão associados a maior parte da área se encontra em relevo plano a suavemente ondulado, onde desenvolvessem naturalmente os Argissolos Vermelho-Amarelo sobreposto às propriedades do Complexo Xingu, que são menos susceptíveis ao intemperismo, mas que naturalmente pode conter perdas excessivas de solo.

No entanto, o grau de Fragilidade Potencial Alta está em proporção representativa, ocupando cerca de $19,57 \%$ da área, que é caracterizado 
principalmente pela influência do grau de inclinação superiores a 20\%, onde está presente solos pouco espessos e desenvolvidos (Neossolo Litólico), o que torna essas áreas altamente suscetíveis a perda do solo.

Tabela 9 - Áreas absolutas e relativas das classes de Fragilidade Potencial do município de Canaã dos Carajás (PA)

\begin{tabular}{lcc}
\hline Fragilidade Potencial & Área $\mathbf{( K m}^{\mathbf{2}} \mathbf{)}$ & Área $\mathbf{( \% )}$ \\
\hline Baixa & 1753,78 & 56,26 \\
\hline Alta & 609,95 & 19,57 \\
\hline Média & 575,24 & 18,45 \\
\hline Muito alta & 165,10 & 5,30 \\
\hline Muito baixa & 13,15 & 0,42 \\
\hline
\end{tabular}

Fonte: Elaborado pelos autores

Destaca-se que a Fragilidade Potencial Média abrange 18,45\% da área mapeada estendendo-se por uma área de 575,23 Km². São áreas que exibem declividade entre 12 a 20\% e influência da litologia da Formação Parauapebas e a formação pedológica mais jovem, o que tornam essas áreas naturalmente susceptíveis a ocorrência de processos erosivos.

Sequencialmente, o grau de Fragilidade Potencial Muito Forte ocorreu em aproximadamente em $5 \%$ da área do município, proporcionada pela grande influência do afloramento rochoso ferrífero da Formação Carajás e relacionadas às áreas com declividade mais elevadas. Logo, as áreas com Fragilidade Potencial muito fraca representam apenas 0,42\%, estão associados aos Latossolos Vermelhos, que são mais porosos e fortemente drenados, desenvolvidos em relevos mais planos, pouco venenáveis quando bem manejados.

Em geral, o mapeamento exibe um indicativo que o potencial natural de erosão no município acompanha as formas da superfície do terreno e as características pedogênicas predominantes no território.

Quanto a Fragilidade Emergente consiste no resultado da relação entre o mapeamento da Fragilidade Potencial apresentado acima sobreposto ao uso e ocupação do solo, que demonstra a situação ambiental atual perante as intervenções 
antrópicas, bem como, os graus de suscetibilidade à erosão de Muito baixa a Muito Alta conforme a figura 8. O mapeamento da Fragilidade Emergente sintetiza e representa as áreas em que o uso do solo potencializa ou não a fragilidade natural do ambiente, face as condições do solo e declividade (PERIÇATO e SOUZA, 2019).

Figura 8 - Fragilidade Emergente do município de Canaã dos Carajás (PA)

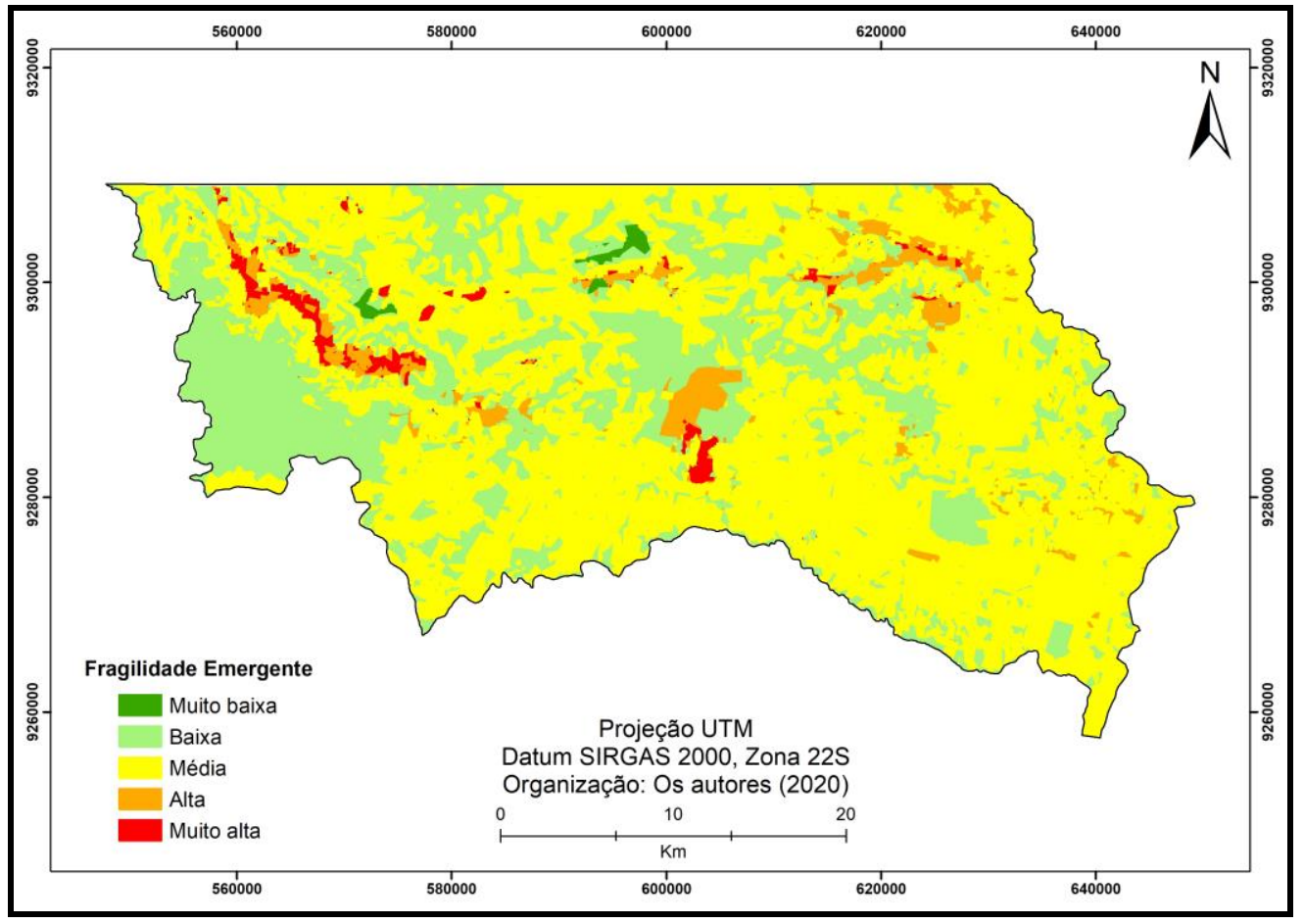

Fonte: Elaborado pelos autores

A espacialização das classes de Fragilidade Emergente pode ser verificada na tabela 10, a partir da qual, tem-se que a classe mais representativa é a Fragilidade Emergente Média correspondendo a 60,16\% da área, identificando-se como áreas com instabilidade no ambiente. Estas áreas representam sinais alarmantes quanto as questões ambientais, caracterizada pela constate intervenção antrópica, principalmente associadas ao grande aumento de áreas destinadas a pastagem, como foi exposto anteriormente na figura 6. 
Tabela 10 - Áreas absolutas e relativas das classes de Fragilidade Potencial do município de Canaã dos Carajás (PA)

\begin{tabular}{lll}
\hline Fragilidade Emergente & Área $\left.\mathbf{( K m}^{\mathbf{2}}\right)$ & Área $\mathbf{( \% )}$ \\
\hline Média & 1873,58 & 60,16 \\
\hline Baixa & 1021,43 & 32,80 \\
\hline Alta & 153,83 & 4,94 \\
\hline Muito alta & 52,34 & 1,68 \\
\hline Muito baixa & 12,96 & 0,42 \\
\hline
\end{tabular}

Fonte: Elaborado pelos autores

Cabe destacar que a dinâmica econômica do município, induzida pela exploração mineral nos anos 2000, experimentou também um processo evolutivo no incremento populacional de 162,83\%, comparando até o ano de 2019 (IBGE, 2019). Dados do MapBiomas (2020) revela também esse grande aumento populacional, expandiu as áreas de infraestrutura urbana em 97,17\% entre 2000 a 2018 . O que proporcionou a elevação da prática da pecuária de corte, constituindo-se então como principal atividade antrópica no município, assim como outras práticas relativas à agricultura de subsistência (SEMDEC, 2016).

Deste modo, as áreas destinadas a pastagem é o fator antrópico que mais influência na determinação da Fragilidade Emergente do município, devido sua grande extensão, assim como foi encontrado por Oliveira et al. (2012), quando avaliou a fragilidade ambiental da bacia hidrográfica do córrego São João (MS). De acordo com Pires et al. (2015), áreas com intensas intervenções agrícolas requerem aplicação de práticas mais conservacionistas, e além da implantação de um plano de reflorestamento que possibilite uma maior preservação do solo.

Em relação ao nível de Fragilidade Emergente Baixa, abrange 32,80\% do território, está associada principalmente por áreas com predomínio de florestas não alteradas e vegetação secundária, ambientes com potencial erosivo naturalmente baixo. Segundo Costa e Rodrigues (2015) a presença da cobertura vegetal atua como principal elemento na proteção do solo por meio da interceptação da água. 
As áreas com nível de Fragilidade Emergente Alta e Muito alta, corresponderam a 4,94\% e 1,68\% do território, respectivamente. Estas áreas estão associadas especialmente ás áreas da unidade geológica Formação Carajás (área não florestada) e a área da unidade de exploração de minério (S11D Eliezer Batista) que consiste no maior complexo minerador da história da empresa Vale, além dos núcleos urbanos implantados nas áreas de mineração.

A região da Formação Carajás detém o maior número de cavidades naturais subterrâneas ferruginosas conhecidas no Brasil (PILÓ e AULER, 2009). As serras, onde se localizam as formações ferríferas, possuem formações vegetais mais abertas com alto grau de especialização e riquíssimo patrimônio espeleológico. No entanto, grande parte dos geossistemas ferruginosos, são diretamente afetadas pela exploração mineral, de forma maiormente irreversível, além de exercerem alterações nos corpos hídricos subterrâneos ou superficiais (ICMBio, 2017).

Segundo Martín et al. (2015) a extração mineral é uma atividade que origina processos erosivos devido a retirada da cobertura vegetal para abertura das lavras e dos locais de depósito de rejeito e estéril, que deixam o solo exposto, aumentando o risco de assoreamento, eutrofização dos corpos hídricos, além da contaminação por elementos tóxicos. Com isso, evidencia-se um alto potencial de instabilidade do ambiente nessas áreas do município.

As áreas de Muito baixa fragilidade, representam apenas 0,42\% do território, associados aos fatores naturais do ambiente mais estáveis.

Desse modo, o mapeamento da Fragilidade Emergente permite identificar que as formas de uso e ocupação do solo, de forma geral, estão contribuindo para intensificação da susceptibilidade natural a erosão no município, os quais demonstram a perda da qualidade ambiental onde as transformações da paisagem estão associadas principalmente à supressão das áreas de florestas com pastagens. 


\section{CONCLUSÃO}

O município de Canaã dos Carajás apresenta baixa susceptibilidade natural aos processos erosivos, porém, quando inserido as formas de uso e cobertura do solo, percebe-se que as atividades antrópicas influenciam na sua instabilidade, potencializando a perda da qualidade ambiental. Sugerindo-se para as áreas identificadas com maior vulnerabilidade, a aplicação de medidas técnicas de prevenção para que este quadro não se intensifique.

Os resultados obtidos poderão contribuir para as interpretações de desenvolvimento e planejamento ambiental do município, de acordo com uma ótica da análise integrada, avaliando tanto as condições naturais, quanto as inseridas pelo homem.

A utilização do geoprocessamento demonstra eficácia na análise empírica da fragilidade ambiental, e pode ser aplicada por gestores ambientais sem demandar recursos financeiros.

\section{REFERÊNCIAS}

ALVES, R.F.; SILVA, S.A.S.; ALVAREZ, W.P. Relação de voçorocas e áreas de fragilidade ambiental na microbacia do Rio Jarauçú no município de Brasil Novo - Pará. Geografia, Ensino \& Pesquisa, v.22, p.01-18, 2018. Disponível em: https://periodicos.ufsm.br/geografia/article/view/31450. Acesso em: 5 set. 2019.

BÖRNER, J.; WUNDER, S. The scope for reducing emissions from forestry and agriculture in the Brazilian Amazon. Forests, v.3, n.3, 2012. Disponível em: https://www.cifor.org/publications/pdf_files/articles/ABorner1201.pdf. Acesso em: 19 set. 2019.

CAMPOS, M.C.C.; MARQUES JÚNIOR, J.; MARTINS FILHO, M.V.; PEREIRA, G.; SOUZA, Z.M.; BARBIER, D.M. Variação espacial da perda de solo por erosão em diferentes superfícies geomórficas. Ciência Rural, Santa Maria, v. 38, n. 9, p.2485-2492. 2008. Disponível em: https://www.scielo.br/pdf/cr/v38n9/a11v38n9.pdf. Acesso: 20 dez. 2019.

CARDOSO, A.C.D.; CÂNDIDO, L.S.; MELO, A.C.C. Canaã dos Carajás: um laboratório sobre as circunstâncias da urbanização, na periferia global e no alvorecer do século XXI. Revista Brasileira de Estudos Urbanos Regionais. v.20, n.1, p.121-140, 2018. Disponível em: https://www.scielo.br/pdf/rbeur/v20n1/en_2317-1529-rbeur-20-01121.pdf. Acesso em 6 set. 2019. 
CLIMATE-DATA. Histórico Climático Canaã dos Carajás. Disponível em: https://pt.climate-data.org/. Acesso em: 11 out. 2019.

CORADO NETO, F.C.; SAMPAIO, F.T.M; VELOSO, M.E.C.; MATIAS, S.S.R.; ANDRADE, F. R.; LOBATO, M.G.R. Variabilidade Espacial da Resistência à Penetração em Neossolo Litólico Degradado. Revista Brasileira de Ciência do Solo, v.39 n.5, p.1353-1361, 2015. Disponível em: https://www.scielo.br/pdf/rbcs/v39n5/0100-0683-rbcs-39-51353.pdf. Acesso em: 12 de jan. 2020.

CORDANI, U.G.; JULIANI, C. Potencial mineral de la amazonia: problemas y desafíos. Revista de Estudios Brasileños, v.6, n.11, p. 91-108, 2019. Disponível em: https://revistas.usal.es/index.php/2386-4540/article/view/reb201961191108. Acesso em: 5 fev. 2020.

COSTA, Y.T.; RODRIGUES, S.C. Relação entre cobertura vegetal e erosão em parcelas representativas de Cerrado. Revista Geografia Acadêmica, v.9, n.2, p. 61-75, 2015. Disponível em: https://revista.ufrr.br/rga/article/view/3160/1816. Acesso em: 6 set. 2019.

COUTINHO, L.M.; ZANETTI, S.S.; CECÍLIO, R.A.; GARCIA, G.O.; XAVIER, A.C. Usos da Terra e Áreas de Preservação Permanente (APP) na Bacia do Rio da Prata, Castelo-ES. Floresta e Ambiente, v.20, n.4, p. 425-434, 2013. Disponível em: https://www.scielo.br/pdf/floram/v20n4/a01v20n4.pdf. Acesso em: 3 set. 2019.

CREPANI, E.; MEDEIROS, J.S.; HERNANDEZ FILHO, P.; FLORENZANO, T.G.; DUARTE, V.; BARBOSA, C.C.F. Sensoriamento Remoto e Geoprocessamento Aplicados ao Zoneamento Ecológico-Econômico e ao Ordenamento Territorial. Relatório Técnico, São José dos Campos, 2001, p.103.

EMPRESA BRASILEIRA DE PESQUISA AGROPECUÁRIA - EMBRAPA. Carta topográfica Canaã dos Carajás (PA). Campinas: Embrapa Monitoramento por Satélite, 2005. Carta: SB-22-Z-A-III-3. Escala 1:50.000.

EMPRESA BRASILEIRA DE PESQUISA AGROPECUÁRIA - EMBRAPA. Sistema Brasileiro de Classificação de Solos. Rio de Janeiro: EMBRAPA Solos, $2^{\circ}$ ed., 2006.

FEIO, G.R.L.; DALL'AGNOL, R. Geochemistry and petrogenesis of the Mesoarchean granites from the Canaã dos Carajás area, Carajás Province, Brazil: Implications for the origin of Archean granites. Lithos, v.154, p.33-52, 2012.

FRANCO, G.B.; BETIM, L.S.; MARQUES E.A.G.; GOMES, R.L.; CHAGAS, C.S. Relação qualidade da água e fragilidade ambiental da Bacia do Rio Almada, Bahia. Brazilian Journal of Geology, v.42, p.114-127, 2013. Disponível em: http://ppegeo.igc.usp.br/index.php/rbg/article/view/8004/7428. Acesso em: 3 set. 2019. 
FURTADO, A. M.M.; PONTE, F.C. Mapeamento de unidades de relevo do Estado do Pará. Revista GeoAmazônia, v.2, n.2, p.56- 67, 2013. Disponível em: http://www.geoamazonia.net/index.php/revista/article/view/10/pdf_9. Acesso em: 3 set. 2019.

INFRAESTRUTURA NACIONAL DE DADOS ESPACIAIS - INDE. Imagem de satélite da pedologia da Amazônia Legal. Rio de Janeiro: INDE, 2012. Escala 1:250.000.

INSTITUTO BRASILEIRO DE GEOGRAFIA E ESTATÍSTICA - IBGE. Estimativas da população, ano 2019. Brasília: IBGE, 2019.

INSTITUTO BRASILEIRO DE GEOGRAFIA E ESTATÍSTICA - IBGE. Manual Técnico de Pedologia, 2a edição. Rio de Janeiro: IBGE, 2007. (Série Manuais Técnicos em Geociências, n. 4).

INSTITUTO BRASILEIRO DE GEOGRAFIA E ESTATÍSTICA - IBGE. Manual Técnico de Uso da Terra, Rio de Janeiro: IBGE, 2013. (Série Manuais Técnicos em Geociências, n. 7)

INSTITUTO CHICO MENDES DE CONSERVAÇÃO DA BIODIVERSIDADE - ICMBio. Plano de Pesquisa Geossistemas Ferruginosos da Floresta Nacional de Carajás. Brasília: ICMBio, 2017.

INSTITUTO CHICO MENDES DE CONSERVAÇÃO DA BIODIVERSIDADE - ICMBio. Plano de manejo da Floresta Nacional de Carajás (Diagnóstico). Brasília: ICMBio, 2016.

INSTITUTO NACIONAL DE PESQUISAS ESPACIAIS - INPE. Imagem de satélite do uso e cobertura da Amazônia Legal. Belém: INPE, 2014. Escala 1:25.000.

KÖPPEN, W.; GEIGER, R. Klimate der Erde. Gotha: Verlag Justus Perthes. 1928.

LIMA, J.B.; SILVA, J.M.P. Dinâmicas econômicas e ordenamentos territoriais dos grandes projetos de mineração no estado do Pará (2009 - 2014): o caso de Paragominas. Revista de Estudos Geoeducacionais, v.6, n.3, p.402-416, 2015. Disponível em: http://www.geosaberes.ufc.br/geosaberes/article/view/486/457 .Acesso em: 3 set. 2019.

LOPES, R. R.; SANTOS, M. M.; CRUZ, T. M. Mineração e conflitos pela posse da terra em Canaã dos Carajás: O caso do acampamento Planalto Serra Dourada. Revista do Programa de Pós-Graduação em Extensão Rural, v.7, n.2, p.117-140, 2018. Disponível em: https://periodicos.ufv.br/rever/article/view/3405/1681. Acesso em: 3 set. 2019.

MARTÍN, D.J.F.; ZAPICO, I.; OYARZUN, R.; LÓPEZ G.J.A.; CUBAS, P. A descriptive and quantitative approach regarding erosion and development of landforms on abandoned mine tailings: New insights and environmental implications from SE Spain. Geomorphology, v. 239, p.1-6, 2015. 
MARTINS, T.I.S.; RODRIGUES, C.S. Análise e mapeamento dos graus de fragilidade ambiental da bacia do médio - baixo curso do rio Araguari, Minas Gerais. Caderno de Geografia, v.22, n.38, p.14-34, 2012. Disponível em: http://periodicos.pucminas.br/index.php/geografia/article/view/3146. Acesso em: 22 jan. 2020.

MEDEIROS, F.B.; MARCATTO, F.S.; SILVEIRA, H.; NOBREGA, M.T. Avaliação da estabilidade de agregados e a vulnerabilidade à erosão ao longo de uma vertente no município de Araruna, região noroeste do Paraná-Brasil. Caderno de Geografia, Belo Horizonte, v.28, n.55, p.845-862, 2018. Disponível em: http://periodicos.pucminas.br/index.php/geografia/article/view/17388. Acesso em: 2 fev. 2020.

OLIVEIRA, R.G.; BACANI, V.M.; SILVA, V.R.; CUNHA, E.R.; FERREIRA, E.M. Análise da fragilidade ambiental da bacia hidrográfica do córrego São João-MS utilizando geoprocessamento. Revista Brasileira de Cartografia, v.64, n.1, p.15-24, 2012. Disponível http://www.seer.ufu.br/index.php/revistabrasileiracartografia/article/view/43773/2303 7. Acesso em: 13 out. 2019.

OLIVEIRA, R.R.S.; VENTURIERI, A.; SAMPAIO, S.N.; LIMA, A.A.; ROCHA, A.J.P. Dinâmica de uso e cobertura da terra das regiões de integração do Araguaia e Tapajós/PA, para os anos de 2008 e 2010. Revista Brasileira de Cartografia, v.68 n.7, p.1411-1424, 2016. Disponível em: https://ainfo.cnptia.embrapa.br/digital/bitstream/item/172706/1/1061 10801-1-PB.pdf. Acesso em: 22 abr. 2020.

OLIVEIRA, V.E.S.; OLIVEIRA, D.C., MARANGOANHA, B.; LAMARÃO, C.N. Geology, mineralogy and petrological affinities of the Neoarchean granitoids from the central portion of the Canaã dos Carajás domain, Amazonian craton, Brazil, Journal of South American Earth Sciences, v.85, p.135-159, 2018.

PAUNGARTTEN, S.P.L.; SANTOS, J.O. Geoprocessamento aplicado a fragilidade ambiental no município Fronteiriço de Oiapoque, Amapá - Brasil. Revista Equador, v.8, $\quad$ n. 2, p.66-77, 2019. Disponível em: https://revistas.ufpi.br/index.php/equador/article/view/9142/5396. Acesso em: 21 set. 2019.

PEIXOTO, C.S.; SILVA, C.A.; MATTOS, S.H.V.L.; BOIN, M.N. Fragilidade potencial e emergente no munícipio de Ivinhema (MS). Revista Eletrônica da Associação dos Geógrafos Brasileiros, v.27, n.15, p.9-30, 2018. Disponível em: https://periodicos.ufms.br/index.php/RevAGB/article/view/5934. Acesso em: 21 set. 2019. 
PERIÇATO, A.J.; SOUZA, M.L. O Estudo da Fragilidade Potencial e Emergente na Bacia Hidrográfica do Rio das Antas, Noroeste do Paraná. Caderno de Geografia, v.29 n.59, p. 1064-1082, $2019 . \quad$ Disponível em: http://periodicos.pucminas.br/index.php/geografia/article/view/19826. Acesso em: 5 de out. 2019.

PILÓ, L.B.; AULER, A.S. Geoespeleologia das cavernas em rochas ferríferas da Região de Carajás, PA. In: CONGRESSO BRASILEIRO DE ESPELEOLOGIA, n. 30., 2009, Montes Claros. Anais do $30^{\circ}$ Congresso Brasileiro de Espeleologia. Montes Claros: Sociedade Brasileira de Espeleologia, p.181-186.

PINESE JÚNIOR, J.F.; CRUZ, L.M.; RODRIGUES, S.C. Monitoramento de erosão laminar em diferentes usos da terra, Uberlândia - MG. Sociedade \& Natureza, Uberlândia, v.20, n.2, p.157-175, 2008. Disponível em: https://www.scielo.br/pdf/sn/v20n2/a10v20n2.pdf. Acesso em: 22 abr. 2020.

PIRES, L.C.; SILVA, L.F.; MENDONÇA, B.G.; BACANI, V.M. Análise da fragilidade ambiental do município de Aquidauana-MS. Caderno de Geografia, v.25, n.43, p.5265, $2015 . \quad$ Disponível em: http://periodicos.pucminas.br/index.php/geografia/article/view/8023. Acesso em: 21 de out. 2019.

PROJETO DE MAPEAMENTO ANUAL DA COBERTURA E USO DO SOLO NO BRASIL MAPBIOMAS. Histórico de dinâmica do uso e ocupação do solo do município de Canaã dos Carajás (PA). Disponível em: https://mapbiomas.org/. Acesso em: 22 abr. 2020.

ROSS, J.L.S. Análise Empírica da Fragilidade dos Ambientes Naturais e Antropizados. Revista do Departamento de Geografia, São Paulo, v.8, 1994.

SCHNEIDER, S.; TARTARUGA, I.G.P. Território e abordagem territorial: das referências cognitivas aos aportes aplicados à análise dos processos sociais rurais. Raízes. v.23, n.1 e 2, p.99-116, 2004. Disponível em: https://mpra.ub.unimuenchen.de/76485/1/Artigo_4.pdf. Acesso em: 2 set. 2019.

SECRETARIA MUNICIPAL DE DESENVOLVIMENTO ECONÔMICO DE CANAÃ DOS CARAJÁS - SEMDEC. Diagnóstico Socioeconômico do Município de Canaã dos Carajás, Estado do Pará. Canaã dos Carajás: SEMDEC, 2016.

SERVIÇO GEOLÓGICO DO BRASIL - CPRM. Imagem de satélite geológico do estado do Pará. Brasília: CPRM, 2019. Escala 1:1.000.000.

SPÖRL, C.; LUCIANO, J.; ROSS, S. Análise Comparativa da Fragilidade Ambiental com Aplicação de Três Modelos. Espaço e Tempo, v.15, p.39-49, 2004. Disponível em: http://www.revistas.usp.br/geousp/article/view/123868. Acesso em: 24 set. 2019. 
STORTO, C.; COCATO, G.P. Análise de Fragilidade Ambiental a partir de Técnicas de Geoprocessamento: Área de Influência da Hidrelétrica de Mauá - PR. Revista Brasileira de Geografia Física, v.11, n.5, p.1694-1708, 2018. Disponível em: https://periodicos.ufpe.br/revistas/rbgfe/article/view/234927/30948. Acesso em: 1 fev. 2020.

TREVISAN, D.P.; MOSCHINI, L.E. Determinação das áreas com fragilidade ambiental do município de São Carlos, São Paulo, Brasil. Geografia, Ensino \& Pesquisa, v.20, n.3, p. 159-167, $2016 . \quad$ Disponível em: https://periodicos.ufsm.br/geografia/article/view/21915/pdf. Acesso em: 25 abr. 2020.

TRICART, J. Ecodinâmica. Rio de Janeiro: IBGE/ SUPREN (Recursos Naturais e Meio Ambiente), 1977.

VALLE, I.C.; FRANCELINO, M.R.; PINHEIRO, H.S.K. Mapeamento da Fragilidade Ambiental na Bacia do Rio Aldeia Velha, RJ. Floresta e Ambiente, v.23, n.2, p.295-308, 2016. Disponível em: https://www.scielo.br/pdf/floram/v23n2/2179-8087-floram-21798087107714.pdf. Acesso em: 22 set. 2019. 